A CASE OF

\section{PERIOSTEAL SARCOMA OF THE FIBULA WITH UNUSUALLY RAPID THOUGH TYPICAL COMPLICATIONS.}

BY F. J. WADHAM, M.R.C.S. ENG., L.R.C.P. LoND., SURGEON TO THE ROYAL ISLE OF WIGHT COUNTY HOSPITAT; AND

E. L. HORSBURGH, M.B., B.S. LoND., HOUSE SURGEON TO THE HOSPITAL.

THE patient, a girl, aged 20, was first admitted to hospital on August 6th, 1912, with a history of pain and slight swelling in the left knee of three months' duration. Up to that time she had always enjoyed excellent health and had followed her occupation of housemaid without difficulty. There was no history of injury or loss of weight. Examination revealed a swelling of about the size of a hen's egg over the upper end of the left tibia. It was hot and tender to the touch. It was firmly fixed and non-fluctuant. No eggshell crackling was obtained. The head of the bone was not apparently expanded. $X$ rays showed the head of the fibula enlarged with broken outline. Spicules of bone were seen in the middle of the growth. A diagnosis of periosteal sarcoma was made. On August 8th a flap amputation in the middle of the thigh was performed. The growth was examined microscopically, and the following report was furnished by the pathologist: "This is a malignant growth, having the structure of a sarcoma. It is composed of large round cells and spindle cells, and is infiltrating and destroying striped muscle. I conclude it is a periosteal growth."

The patient recovered from the operation extremely well and a primary union was obtained. She was, however, kept in the hospital for observation until Oct. 4th, when she left apparently free from recurrence. She presented herself next at the out-patient department on Nov. $36 \mathrm{th}$, complaining of pain and stiffness in the left groin. Examination showed a firmly fixed, stony hard mass in the left iliac fossa. Masses were also felt in the saphenous ring and following the course of the femoral vein upwards. Recurrence was diagnosed, and the patient was readmitted, but no operation could be undertaken. The patient, beyond the pain in the groin, was very well, got about on crutches with ease, and had not lost any weight. As it was considered useless to detain her in hospital she was discharged on Dec. 8th, 1912.

On Dec. 19th the patient again presented herself at the out-patient department suffering from most urgent dyspncea and cough. Examination showed the left chest to be immovable; absolute dulness front and back up to the clavicle. The heart apex beat was in the right nipple line and breath sounds were quite absent. Nothing abnormal was discovered in the right chest. Fluid was diagnosed, and the chest was aspirated below the angle of the scapula and two pints of sanguineous fluid were withdrawn. The symptoms were relieved. The displacement of the heart persisted; the apex beat was now hilf an inch internal to the right nipple line. The fluid gradually reaccumulated, and the patient's general condition became so bad that further aspiration was deemed inadvisable. She gradually sank and died at 8.30 A.M. on Dec. 30th.

Necropsy. - The thorax and abdomen were opened in the usual way. The left chest contained more than a gallon of blood-stained fluid. When the pleura was swabbed dry it was seen that the left lung was completely collapsed and full from apex to base of solid growth which cut like cartilage. The growth appeared to follow very closely the bronchial tree. The right lung was also studded throughout with recurrent nodules, the largest size being about that of a two-shilling piece. There was, however, a considerable amount of normal lung tissue, but there was no evidence of emphysema. The pleura on the left side was covered with hard growth, which was heaped up to the extent of quite half an inch from the serous lining. Scarcely an inch of the pleura was unaffected. The visceral pleura was affected on both sides, though chiefly on the left. The pleural surface of the diaphragm was covered throughout with growth, though here it was in places heaped up to quite an inch in height. The recurrence in the groin was then examined. There was a mass of stony, hard growth all round the saphenous vein, surrounding also the femoral vein, the external iliac vein, and some way up the inferior vena cava. The circumference of this recurrence all the way up was about the size of the closed adult fist. There was considerable cedema of the amputation stump in consequence of this.

The case is, we think, of interest: (1) in proving the intense malignancy of these tumours; (2) in the typical distribution of the metastatic deposits vi $\hat{a}$ the blood stream to the lungs; (3) from the complete lack of symptoms of recurrence till just at the end of the illness; (4) from the post-mortem examination, which showed an astounding amount of growth for the length of the history ; and (5) from the intense rapidity of the sequelæ.

Isle of Wight.

\section{A NOTE ON}

\section{THE USE OF SUGAR IN HEART DISEASE.}

\section{By STANley E. DENYER, C.M.G., M.D. Cantab.,} F.R.C.S. ENG.

Physiologists have experimentally proved the nutritive value of sugar upon heart muscle. It has been established clinically that it undoubtedly gives good results in some forms of heart disease. In other forms no benefit has been observed from its use. The only way to get a classification of the value of remedies is to put on record the cases we treat with those remedies, both the failures and the successes. The failures are apt to be unrecorded, as they do not cause so much interest as the successes, but they are quite as important for statistical purposes. From the few inquiries that I have made, cases with odema, cases with anginal pain, and cases where cardiac disease is secondary to renal disease do not seem to be improved by it. In a case of general paralysis of the insane, where the pulse was failing, I tried sugar, but it had no effect. In the following case the effect was so marked that I feel sure the patient's life was saved by it. The clinical history is as follows.

The patient, aged 77 years, had an irregularity of the pulse for some years. On Nov. 8th, 1912, she had a bad heart attack, with rapid, irregular, feeble pulse, cyanosis, and attacks of paroxysmal breathing, which occurred about 5 or 6 A.M. There was no odema at this time, nor at any time during the illness. I saw the patient at $7 \mathrm{~A}$.M. and ordered inhalation of amyl nitrite, which gave temporary relief. This condition continued for some days, the patient steadily getting worse in spite of digitalis, digitalin, strychnine, dry-cupping, leeching, and frequent inhalations of oxygen. She said that the dry-cupping gave a great sensation of ease in breathing, and the oxygen certainly did her a lot of good, but the improvement was only temporary. On the 14th the patient seemed to be dying; when seen at 11 P.M. it seemed doubtful if she would live through the night. Her relatives thought even worse of her and were firmly convinced that she was going to die, and an experienced nurse whom $I$ had in charge of the case thought there was little hope. I ordered some lumps of ordinary white sugar to be given in milk, and added some syrup to her medicine, telling them to give her four ounces of sugar during the night. In the morning I found the patient very weak, but less cyanosed and with a stronger, slower pulse. Digitalis had been omitted as well as digitalin, as these had not any effect on the heart or pulse. Four ounces of sugar were ordered during the ensuing 12 hours, and after that it was continued in smaller quantities for some weeks. The patient made a slow but steady improvement, the breathing attacks getting less frequent and the pulse stronger and more regular. Her general weakness was very great and she gained strength only very slowly. By the end of February of this year she was able to go out into the garden for a ferw minutes, and to walk up and down stairs. Hull. 